between the cities were consistent when comparing the London and Singapore smokers (overall, $2.0 \pm 1.1$ vs $1.6 \pm 1.1$, p < 0.001 ) and non-smokers (overall, $2.0 \pm 1.4$ vs $1.4 \pm 0.8, \mathrm{p}<$ 0.001 ) (Table 1). Londoners experienced more disgust when viewing the images $(79 \%$ vs $53 \%, \mathrm{p}<0.001)$ and felt they were more effective deterrents $(51 \%$ vs $35 \%, \mathrm{p}=0.011)$. One-in-five participants in Singapore were unaware of the association between smoking and lung cancer, despite it being the most deterring risk; blindness was the least well-known consequence in London $(24 \%)$ and Singapore $(34 \%, \mathrm{p}=0.075)$ despite being ranked ahead of stroke, oral cancer, and in smokers, ahead of heart disease for importance to prevent/treat.

\begin{tabular}{|c|c|c|c|c|c|c|c|c|c|}
\hline \multirow[b]{2}{*}{$\begin{array}{l}\text { Processing } \\
\text { (I5) (SD) }\end{array}$} & \multicolumn{3}{|c|}{ All } & \multicolumn{3}{|c|}{ Non-smokers } & \multicolumn{3}{|c|}{ Smokers } \\
\hline & Sing & London & $\mathrm{p}$ & Sing & London & $\mathrm{p}$ & Sing & London & $\mathrm{p}$ \\
\hline $\begin{array}{l}\text { Carefully } \\
\text { read labels }\end{array}$ & $\begin{array}{l}1.8 \\
(1.1)\end{array}$ & $2.2(1.2)$ & 0.004 & $\begin{array}{l}1.6 \\
(0.9)\end{array}$ & $2.1(1.3)$ & 0.024 & $\begin{array}{l}1.9 \\
(1.2)\end{array}$ & $2.4(1.1)$ & 0.028 \\
\hline $\begin{array}{l}\text { Often read } \\
\text { labels }\end{array}$ & $\begin{array}{l}1.7 \\
(1.1)\end{array}$ & $2.2(1.3)$ & $<0.001$ & $\begin{array}{l}1.5 \\
(0.9)\end{array}$ & $2.2(1.4)$ & 0.001 & $\begin{array}{l}1.9 \\
(1.2)\end{array}$ & $2.3(1.0)$ & 0.095 \\
\hline $\begin{array}{l}\text { Ever talked } \\
\text { about }\end{array}$ & $\begin{array}{l}1.5 \\
(1.1)\end{array}$ & $2.2(1.4)$ & $<0.001$ & $\begin{array}{l}1.6 \\
(1.1)\end{array}$ & $2.3(1.5)$ & 0.001 & $\begin{array}{l}1.5 \\
(1.2)\end{array}$ & $2.0(1.1)$ & 0.039 \\
\hline $\begin{array}{l}\text { Often think } \\
\text { about }\end{array}$ & $\begin{array}{l}1.6 \\
(1.0)\end{array}$ & $2.4(1.4)$ & $<0.001$ & $\begin{array}{l}1.5 \\
(0.9)\end{array}$ & $2.5(1.4)$ & 0.001 & $\begin{array}{l}1.8 \\
(1.1)\end{array}$ & $2.4(1.3)$ & 0.006 \\
\hline $\begin{array}{l}\text { Inc. when } \\
\text { not in sight }\end{array}$ & $\begin{array}{l}1.3 \\
(0.7)\end{array}$ & $1.8(1.1)$ & $<0.001$ & $\begin{array}{l}1.1 \\
(0.6)\end{array}$ & $1.8(1.2)$ & 0.001 & $\begin{array}{l}1.4 \\
(0.9)\end{array}$ & $1.8(1.0)$ & 0.040 \\
\hline $\begin{array}{l}\text { Kept labels } \\
\text { as reminder }\end{array}$ & $\begin{array}{l}1.0 \\
(0.3)\end{array}$ & $1.3(0.8)$ & 0.001 & $\begin{array}{l}1.0 \\
(0.2)\end{array}$ & $1.3(0.9)$ & 0.021 & $\begin{array}{l}1.0 \\
(0.3)\end{array}$ & $1.3(0.8)$ & 0.023 \\
\hline
\end{tabular}

Conclusion A desensitisation to graphic health warning labels occurs with extended exposure. Non-smokers are prone to the same desensitisation as smokers are. In pre-empting this, the awareness and impact of specific health risks need to be actively utilised, in concerted public health campaigns, to help maintain label efficacy.

\section{S78 ELECTRONIC CIGARETTE ADVERTISING IMPACTS ADVERSELY ON SMOKING BEHAVIOUR WITHIN A LONDON STUDENT COHORT: A CROSS-SECTIONAL SURVEY}

${ }^{1} \mathrm{C}$ Ratneswaran, ${ }^{2} \mathrm{R}$ Judge, ${ }^{1} \mathrm{M}$ Colquhoun, ${ }^{3} \mathrm{~J}$ Steier, ${ }^{1} \mathrm{TK}$ Khong. ${ }^{2}$ St George's, University of London, London, UK; ${ }^{2}$ Kingston University, London, UK; ${ }^{3}$ Guy's and St Thomas' NHS Foundation Trust, London, UK

\subsection{6/thoraxjnl-2015-207770.84}

Introduction In contrast to tobacco smoking, electronic cigarette ("vaping") advertisement has been approved in the UK since January 2013. Currently, there are 2.6 million e-cigarette users in the UK. The impact of e-cigarette advertisement on tobacco use has not been studied in detail. We hypothesised that e-cigarette advertisement impacts on smoking behaviour.

Methods A structured survey was constructed to assess the impact of e-cigarette advertising on the perceived social acceptability of cigarette smoking; and, on trying both cigarettes and ecigarettes (on a scale of 1 to $5 /$ 'not at all' to 'a great deal'). The survey was administered between January to March 2015 to
London university students, before and after viewing 5 UK adverts including a TV commercial.

Results Data were collected from 106 participants $(22 \pm 2$ years, 66\%male), comprising 34 current cigarette-smokers, 57 nonsmokers and 15 ex-smokers. There were 17 vapers, 82 nonvapers and 7 ex-vapers. After viewing the adverts, both smokers $(2.6 \pm 1.0$ vs $3.8 \pm 1.1, \mathrm{p}=0.0002)$ and non-smokers $(3.2 \pm$ 0.7 vs $3.7 \pm 0.8, \mathrm{p}=0.004)$ felt e-cigarette advertising increased the social acceptability of smoking; and, both smokers and non-smokers were more likely to try e-cigarettes $(3.6 \pm 1.0$ and $2.6 \pm 1.0$ respectively, $\mathrm{p}<0.0001)$ as well as conventional cigarettes $(3.4 \pm 1.0$ and $1.5 \pm 0.9$ respectively, $\mathrm{p}<0.0001)$. Additionally after viewing, vapers felt e-cigarettes were 'less effective' at helping people stop smoking compared to before $(3.6 \pm 0.7$ vs $4.0 \pm 0.6, p=0.004)$.

Conclusion E-cigarette advertising encourages e-cigarette and conventional cigarette use in young smokers and non-smokers. The adverts impact on the social acceptability of smoking without regarding the importance of smoking cessation.

\section{S79 THE ELECTRONIC CASE-BASED DISCUSSION; A NOVEL TEACHING METHOD APPLIED TO SMOKING CESSATION}

AJK Wilkinson. East and North Herts NHS Trust, Stevenage, UK

\subsection{6/thoraxjnl-2015-207770.85}

Introduction Current smoking cessation training in U. K. medical schools fails to equip junior doctors with the skills necessary to effectively combat the leading preventable cause of death and disease. ${ }^{1}$ Here I present a novel teaching method using an electronic Case-Based Discussion (eCBD) which streamlines the process of workplace-based assessments, facilitates high-quality learning and provides new insights into what students know about this critically important subject.

Methods An electronic learning module was developed by the author based on existing NICE guidelines. ${ }^{2}$ Candidates described a case of a smoker they had seen and were quizzed about the case by the learning module with some instant feedback, then deeper discussion with the author via e-mail. When the candidate was ready a CBD form was completed. Finally feedback was collected using an anonymous, online feedback form.

Results Thirty students and junior doctors have completed the eCBD. The eCBD had excellent feedback with 94\% rating the eCBD as "very useful" and 100\% feeling more confident in giving smoking cessation advice. Ninety-four percent rated the eCBD as "easier" or "much easier" to arrange and 53\% rated it "much better" at assessing knowledge than conventional CBDs.

Analysis of responses revealed deficiencies in knowledge of medications to treat tobacco dependence; $97 \%$ knew of nicotine replacement therapy (NRT) but knowledge of some formulations was poor (none mentioned oral strips, 3\% microtabs, $17 \%$ lozenges); $43 \%$ knew of varenicline and $40 \%$ bupropion. Only $37 \%$ thought that combination NRT was safe and effective and thematic analysis revealed widespread concerns about the risks of overdose. $57 \%$ would consider recommending e-cigarettes for selected patients although only $7 \%$ had already recommended them to patients.

Conclusions The eCBD can be an effective method of encouraging learning in important and neglected subject areas. It also illustrates an often-wasted opportunity to collect data from online learning modules that could guide curriculum development and facilitate better training in future. 


\begin{tabular}{|c|c|c|c|}
\hline NICE recommendation & \multicolumn{3}{|c|}{ eCBD responses } \\
\hline \multicolumn{4}{|c|}{ Is combination nicotine replacement therapy (NRT) safe and effective? } \\
\hline $\begin{array}{l}\text { Yes - "offer licensed NRT (usually a combination } \\
\text { of patches with a fast-acting product...) to all } \\
\text { people who smoke" }\end{array}$ & Yes No & $\begin{array}{l}\text { Don't } \\
\text { know }\end{array}$ & $\begin{array}{l}\text { Maybe for } \\
\text { certain } \\
\text { patients }\end{array}$ \\
\hline & $37 \% \quad 23 \%$ & $40 \%$ & - \\
\hline \multicolumn{4}{|c|}{ Would you recommend e-cigarettes for smoking cessation? } \\
\hline $\begin{array}{l}\text { No - "Encourage people who are already } \\
\text { using...electronic cigarettes to switch to a } \\
\text { licensed product" }\end{array}$ & $10 \% \quad 20 \%$ & $23 \%$ & $47 \%$ \\
\hline Would you offer NRT to help cut-down on sme & king? & & \\
\hline $\begin{array}{l}\text { Yes - "Offer all types of licensed NRT to people } \\
\text { who smoke, as part of a harm-reduction strategy" }\end{array}$ & $77 \% \quad 0 \%$ & $23 \%$ & - \\
\hline
\end{tabular}

\section{REFERENCES}

1 Raupach T, Al-Harbi G, McNeill A, Bobak A, McEwen A. Smoking cessation education and training in U. K. Medical schools: a national survey. Nicotine Tob Res. 2015;17(3):372-375

2 National Institute for Health and Clinical Excellence. Smoking cessation in secondary care: acute, maternity and mental health services. PH48. London: NICE, 2013

\section{S80 GAME ON? THE GAMIFICATION OF MHEALTH APPS IN THE CONTEXT OF SMOKING CESSATION}

M Ahmed, Y Sherwani, M Muntasir, A El-Hilly, S Iqbal, S Siddiqui, Z Al-Fagih, O Usmani, A Eisingerich. Imperial College London, London, UK

\subsection{6/thoraxjnl-2015-207770.86}

Introduction and objectives Increasing emphasis has been placed on behavioural therapy in smoking cessation efforts. mHealth aims to join today's arsenal of smoking cessation techniques. Many apps are utilising 'gamification' (the use of game design elements in non-game contexts) as a tool to drive positive behaviour change. However, a significant knowledge gap currently remains regarding how gamification can affect health behaviour. Our study seeked to elucidate the motivational mechanisms exploited by gamification in promoting positive health behaviours in the context of smoking cessation, with a view to generating recommendations on how to create effective gamified mHealth interventions.

Methods We conducted a qualitative longitudinal study using a sample of 16 smokers divided into two cohorts. The first cohort used a non-gamified mHealth intervention, whilst the second used a gamified mHealth intervention. The added game components allowed us to isolate the effects of gamification. Each participant underwent 4 one-on-one, semi-structured interviews over a period of 5 weeks. Interviews were transcribed verbatim after which thematic analysis was undertaken.

Results We observed that perceived behavioural control and intrinsic motivation acted as positive drivers to game engagement and consequently positive health behaviour. Importantly, external social influences exerted a negative effect. We identified three critical factors, whose presence was necessary for game engagement; purpose (explicit purpose known by the user), user alignment (congruency of game and user objectives), functional utility (a well-designed game). We summarise these findings in a framework (Figure 1), which we propose to guide the development of gamified mHealth interventions.

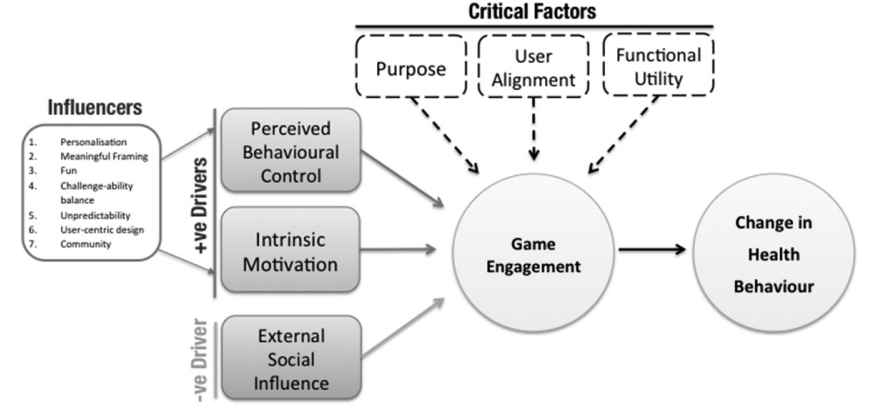

Abstract S80 Figure 1 A framework proposing effective use of gamification to promote positive health behaviour

Conclusions Our framework outlines the characteristics critical to consider when developing any gamified mHealth intervention to promote a particular health behaviour. Gamification holds the potential for low-cost, highly effective mHealth solutions that may replace or supplement the behavioural support component found in current smoking cessation programmes. Our proposed framework has been built on evidence specific to smoking cessation, but is versatile and can be extended to health interventions in other disease categories. Future research is now required to evaluate the effectiveness of the above framework directly against current behavioural support therapy interventions in smoking cessation.

\section{S81 FEASIBILITY AND UPTAKE OF ENHANCED SMOKING CESSATION SERVICES WITHIN AMBULATORY HIV CARE}

${ }^{1} \mathrm{C}$ Kyriacou, ${ }^{1} \mathrm{~N}$ Stewart, ${ }^{1} \mathrm{~A}$ Melville, ${ }^{1} \mathrm{~J}$ Brown, ${ }^{1} \mathrm{~K}$ Edwards, ${ }^{1} \mathrm{R}$ Lloyd, ${ }^{1} \mathrm{M}$ Johnson, ${ }^{1} \mathrm{~J}$ Flint, ${ }^{2} \mathrm{~A}$ Rodger, ${ }^{1} \mathrm{M}$ Lipman. ${ }^{1}$ Royal Free London NHS Trust, London, UK; ${ }^{2}$ Department of Infection and Population Health, University College London, London, UK

\subsection{6/thoraxjnl-2015-207770.87}

Background HIV infected individuals are at increased risk of smoking-related illness and smoking rates amongst populations with HIV are often significantly higher than the general population. Interventions that reduce the prevalence of smoking in this population are urgently required.

Aims We sought to establish the impact of initiating regular smoking screening and advice by healthcare assistants (HCAs) or nurses as part of routine care appointments in a HIV ambulatory care service.

Methods Individuals attending for ambulatory HIV care appointments were asked brief screening questions regarding cigarette smoking by Healthcare Assistants (HCAs) or nurses. This was completed whilst clinical observations were performed, allowing this intervention to be delivered as part of routine care. Those who were current smokers were given Very Brief Advice (VBA) regarding smoking cessation and offered referral to smoking cessation services. The number of referrals to smoking cessation services was compared to the six months prior to the introduction of the enhanced service.

Results 1,031 individuals were screened between October 2014 and March 2015: 262 (25\%) reported that they were current smokers. $248(93 \%)$ of these smokers were provided with VBA and the opportunity of referral to smoking cessation services. Of these, 103 (38\%) accepted referral compared to 6 referrals from the HIV outpatient service in the preceding 6 months.

Conclusions An intervention to ask service users about smoking and provide smoking cessation advice can be undertaken as part 